\title{
Significance of estimating the glomerular filtration rate for the management of hypertension in type 2 diabetes with microalbuminuria
}

\author{
Motonobu Nishimura ${ }^{1}$, Yasuhisa Kato ${ }^{2}$, Tsuyoshi Tanaka ${ }^{3}$, Ryohei Todo ${ }^{4}$, Atsuhito Tone ${ }^{5}$, Kazunori Yamada ${ }^{6}$, \\ Sumire Ootani $^{7}$, Yojiro Kawabe ${ }^{8}$, Hideyuki Yoshizumi ${ }^{9}$ and Yoshiharu Hoshiyama ${ }^{10}$
}

The Home Blood Pressure for Diabetic Nephropathy (HBP-DN) study is a prospective cohort study to determine the optimal home blood pressure (HBP) required to improve the prognosis of type 2 diabetic patients with microalbuminuria. The glomerular filtration rate (GFR) is heterogeneous in microalbuminuric diabetic patients. The first step of the HBP-DN study explored the significance of estimating GFR for the identification of patients for whom HBP measurement would be more helpful. The patients were divided into two groups based on their estimated GFR (eGFR): a low eGFR group (eGFR $<60 \mathrm{ml} \mathrm{min}^{-1}$ per $1.73 \mathrm{~m}^{2}, N=75$ ) and a preserved eGFR group (eGFR $\geqslant 60 \mathrm{ml} \mathrm{min}^{-1}$ per $1.73 \mathrm{~m}^{2}, N=193$ ). HBP, variability of $\mathrm{HBP}$ and a previous history of vascular complications were compared between the two groups. The number of antihypertensive drugs used for the patients and the s.d. of home systolic blood pressure (HSBP) in the low eGFR group were significantly higher than those in the preserved eGFR group. A stepwise multiple linear regression analysis also revealed that the low eGFR group was independently correlated with the s.d. of HSBP. A multiple logistic regression analysis revealed that a low eGFR was an independent risk factor for coronary heart disease and advanced retinopathy. Estimating the GFR is important to identify patients with elevated blood pressure variability, as well as those with a high risk of vascular complications.

Measuring HBP would be more helpful for the effective and safe treatment of hypertension in patients with a low eGFR than in those with a preserved eGFR.

Hypertension Research (2013) 36, 705-710; doi:10.1038/hr.2013.22; published online 4 April 2013

Keywords: blood pressure variability; diabetic nephropathy; estimated glomerular filtration rate; home blood pressure; microalbuminuria

\section{INTRODUCTION}

The leading cause of end-stage renal disease in Europe, the United States and Japan is diabetic nephropathy. The risk of cardiovascular death increases as diabetic nephropathy progresses. ${ }^{1}$ Therefore, diabetic nephropathy worsens both activity in daily life and life prognosis. Microalbuminuria is considered to be one of the first signs of diabetic nephropathy. Remission/regression of diabetic nephropathy can be obtained in $\sim 30 \%$ of patients with microalbuminuria. $^{2,3}$ The control of hypertension is as important as the control of hyperglycemia for the induction of remission/regression in patients with microalbuminuria. ${ }^{3}$ Home blood pressure (HBP) measurement has become popular with both doctors and patients. HBP measurement can improve the control of hypertension. ${ }^{4} \mathrm{HBP}$ can predict cardiovascular diseases and end-stage renal disease better than clinic blood pressure (CBP).$^{5-8} \mathrm{HBP}$ measurement is thus considered to be useful for the treatment of hypertension. The Japanese Society of Hypertension (JSH) 2009 guidelines set the target HBP at $<125 / 75 \mathrm{~mm} \mathrm{Hg}$ for patients with diabetes and chronic kidney disease (CKD). ${ }^{9,10}$ However, there is not enough information currently available about the optimal HBP for diabetic patients. The Home Blood Pressure for Diabetic Nephropathy (HBP$\mathrm{DN}$ ) study is a 3-year prospective cohort study that was designed to determine the optimal HBP to improve the prognosis of type 2 diabetic patients with microalbuminuria.

Kidney disease in type 2 diabetes is more heterogeneous than in type 1 diabetes. ${ }^{11,12}$ Albuminuria does not always precede the decline in the glomerular filtration rate (GFR). ${ }^{11,13,14}$ The diabetes treatment guidelines therefore recommend the assessment of both albuminuria and GFR. ${ }^{15}$ The significance of assessing GFR for evaluating the risk of mortality and vascular complications has been

\footnotetext{
${ }^{1}$ National Hospital Organization Chiba-East National Hospital, Chiba, Japan; ${ }^{2}$ National Hospital Organization Nagoya Medical Center, Nagoya, Japan; ${ }^{3}$ National Hospital Organization Mie Chuo Medical Center, Tsu, Japan; ${ }^{4}$ National Hospital Organization Osaka Medical Center, Osaka, Japan; ${ }^{5}$ National Hospital Organization Okayama Medical Center, Okayama, Japan; ${ }^{6}$ National Hospital Organization Kyoto Medical Center, Kyoto, Japan; ${ }^{7}$ National Hospital Organization, Saitama National Hospital, Wako, Japan; ${ }^{8}$ National Hospital Organization Ureshino Medical Center, Ureshino, Japan; ${ }^{9}$ National Hospital Organization Kyushu Medical Center, Fukuoka, Japan and ${ }^{10}$ Yokohama Soei University, Yokohama, Japan

Correspondence: Dr M Nishimura, Department of Internal Medicine, National Hospital Organization Chiba-East National Hospital, 673, Nitonachou, Chuou-ku, Choba City, Chiba 2608712 , Japan. 
almost established. ${ }^{16,17}$ However, whether a difference exists in the HBP variability between patients with low GFR and preserved GFR remains to be elucidated. Recently, day-by-day variability of blood pressure is recognized as one of the index that should be analyzed from the data of HBP. The variability of blood pressure can be predictors of vascular complications independent of the mean systolic blood pressure. ${ }^{18-21}$ HBP measurement would be more helpful for the safe and effective treatment of hypertension of patients with elevated blood pressure variability. Although all patients with hypertension should measure HBP, it is not easy to supply automatic devices for HBP measurement to all of these patients. Therefore, it is important to identify the patients for whom HBP measurement would be more helpful.

The first step of the HBP-DN study explored the significance of estimating the GFR for identifying patients for whom HBP measurement would be more helpful. Therefore, the baseline data of the HBPDN study were analyzed, and differences in HBP and its variability between the low and preserved estimated GFR (eGFR) groups were investigated. The study also compared the rates of chronic vascular complications such as retinopathy, coronary heart disease (CHD) and stroke between the two groups of subjects based on the eGFR.

\section{METHODS}

The HBP-DN study is a multicenter study being performed as part of the National Hospital Organization Multi-Center Clinical Research for EvidenceBased Medicine. Subjects of both sexes were recruited from 29 hospitals belonging to the Japan National Hospital Organization. This study has two successive phases. The first phase consisted of a period of evaluation with two separate visits (visits 1 and 2). The urinary albumin-to-creatinine ratio (ACR) was measured using morning urine sample. The inclusion criteria were: (1) patients with type 2 diabetes, (2) ACR was between 30 and $300 \mathrm{mg}$ per $\mathrm{g}$ creatinine twice in succession (visits 1 and 2), (3) patients were 20 to 75 years of age and (4) hemoglobin Alc (HbAlc) at visit 1 was $<9.4 \%$ (National Glycohemoglobin Standardization Program (NGSP)). The exclusion criteria were: (1) pregnancy, (2) patients who could not use the automatic cuffoscillometric device at home, (3) those with malignant tumors, (4) patients whose blood pressure should not be lowered too much (that is, patients with orthostatic hypotension, a history of cerebral infarction within 6 months before consent acquisition), (5) nondiabetic nephropathy, (6) congestive heart failure and (7) urinary tract infection or neurogenic bladder. The second phase is a 3 -year follow-up of the patients (visits 3 through 6). The baseline data were obtained on visit 3. A total of 311 patients were recruited from April 2008 to June 2009. Among these patients, 268 patients fulfilled the criteria.

The HBP was measured once in the morning and once in the evening, with the subjects in the sitting position, using an automatic cuff-oscillometric device (Omron HEM-7471C, Kyoto, Japan). The patients were asked to record their blood pressure readings for 7 days on paper and to submit it to their physician on visit 3 and every 6 months thereafter. Therefore, one set of HBP records included the morning and evening HBP record for 7 days. The morning home systolic blood pressure (HSBP), morning home diastolic blood pressure (HDBP), evening HSBP and evening HDBP of each record were determined from the mean of the seven blood pressure measurements. All HSBP and all HDBP values were determined as the mean of the morning and evening HSBP and HDBP measurements. The day to day variability of the HBP was assessed by calculating the s.d. of the measurements of the morning and evening HBP for 7 days. The $\triangle$ HBP (maximum HBP - minimum HBP) and the morningevening differences (MEdifs) in HBP were also calculated. The CBP was measured with the subjects in the sitting position with the same automatic cuff-oscillometric device presented to participants. This is an observational study, and there are no specific recommendations with regard to the management of hypertension, including the type of drug treatment or blood pressure goal.

The eGFR was calculated by the Modified Diet for Renal Disease study equation modified for Japanese patients with CKD: eGFR $\left(\mathrm{ml} \mathrm{min}^{-1}\right.$ per $\left.1.73 \mathrm{~m}^{2}\right)=194 \times \mathrm{Cr}^{-1.094} \times \mathrm{Age}^{-0.287}(\times 0.739$, if female $) .22$ Patients were stratified by their eGFR values $\left(\mathrm{ml} \mathrm{min}^{-1}\right.$ per $\left.1.73 \mathrm{~m}^{2}\right)$ into five CKD stages according to the National Kidney Foundation guidelines: $:^{23}$ stage 1, eGFR $\geqslant 90$; stage 2, eGFR 60-89; stage 3, eGFR 30-59; stage 4, eGFR 15-29; stage 5, eGFR $<15 \mathrm{ml} \mathrm{min}^{-1}$ per $1.73 \mathrm{~m}^{2}$. The patients in stages 1 and 2 were combined as the preserved eGFR group and those in stages $3-5$ were combined as the low eGFR group.

The geometric mean of the ACR on visits 1 and 2 was used as the baseline ACR. The CBP, HBP and laboratory data except for the ACR obtained on the day of visit 3 were used as the baseline data. The recommended BP for patients with diabetes is $<130 / 80 \mathrm{~mm} \mathrm{Hg}$ according to the hypertension guidelines of the Japanese Society of Hypertension (JDS) 2009. ${ }^{9}$ Therefore, hypertension is defined as a blood pressure level $>130 / 80 \mathrm{mmHg}$ or the use of antihypertensive medication.

\section{Definitions of the outcome used in this study}

CHD included acute myocardial infarction and angina pectoris. Patients with a previous history of coronary interventions were also considered to have CHD. Acute myocardial infarction was defined by the presence of $\geqslant 2$ of the following: typical chest pain, electrocardiographic changes and increased cardiac enzyme concentrations. Angina pectoris was diagnosed if there was chest pain and documented electrocardiographic signs of coronary ischemia.

Stroke was defined as a neurological deficit with symptoms continuing for more than $24 \mathrm{~h}$ whose focus was confirmed by CT or MRI. Silent brain infarction and transient ischemic attack were not included as stroke.

Retinopathy was classified as absent, background or proliferative. Advanced retinopathy was defined as proliferative retinopathy or a history of retinal photocoagulation.

\section{Statistical analyses}

A statistical software package (SPSS, version 11, Chicago, IL, USA) was used for the analyses. The data are presented as the means \pm s.d. values unless otherwise stated. Comparisons of the data from two groups were made using unpaired Student's $t$-test. The $\chi^{2}$ test was used for categorical data. Stepwise multiple linear regression analyses were used to compare the relationship between the variability of HBP and various factors. The multiple logistic regression analyses with the forward selection method were used to study the association of variables with a previous history of vascular complications.

The study protocol and informed consent procedures were approved by the Ethics Committee of Japan National Hospital Organization. All patients gave their written informed consent. This protocol was submitted to the UMINClinical Trial Registration on 1 September 2007, and its unique trial number is UMIN000000804.

\section{RESULTS}

\section{Comparison of the baseline clinical characteristics of patients} between the preserved eGFR group and low eGFR group

The proportion of patients in each CKD stage were: stage 1, 14.9\%; stage $2,57.1 \%$; stage $3,27.2 \%$; stage $4,0.8 \%$; and stage $5,0 \%$. Patients with stage 1 and 2 CKD were combined as the preserved eGFR group ( $n=193$ ), and patients with stage 3 and 4 CKD were combined as the low eGFR group $(n=75)$. The clinical and metabolic parameters, except for blood pressure at baseline, are summarized for all patients, and for the preserved eGFR group and the low eGFR group (Table 1). The patients in the low eGFR group were significantly older than those in the preserved eGFR group $(P<0.05)$. The ACR of the low eGFR group was significantly higher than that of the preserved eGFR group $(P<0.05)$. The HbAlc and high-density lipoprotein cholesterol levels of the preserved eGFR group were significantly higher than those of the low eGFR group.

The clinical characteristics associated with the blood pressure at baseline were summarized for all patients, the preserved eGFR group and the low eGFR group (Table 2). There were no significant differences in the CBP and HBP between the low and preserved 
Table 1 Baseline clinical characteristics of all patients, the preserved eGFR group and the low eGFR group

\begin{tabular}{|c|c|c|c|c|}
\hline & Total & Preserved eGFR & Low eGFR & P-value \\
\hline Number, patients & 268 & 193 & 75 & \\
\hline Age, years & $64.4 \pm 8.0$ & $63.7 \pm 8.4$ & $66.1 \pm 6.7$ & * \\
\hline Gender & $\begin{array}{l}\text { Male } 173, \\
\text { Female } 95\end{array}$ & $\begin{array}{l}\text { Male } 128, \\
\text { Female } 65\end{array}$ & $\begin{array}{l}\text { Male } 45, \\
\text { Female } 30\end{array}$ & \\
\hline $\begin{array}{l}\text { Duration of diabetes, } \\
\text { years }\end{array}$ & $14.8 \pm 9.4$ & $14.3 \pm 16.5$ & $16.5 \pm 10.1$ & \\
\hline $\mathrm{BMI}, \mathrm{kg} \mathrm{m}^{-2}$ & $25.1 \pm 4.03$ & $25.1 \pm 4.04$ & $25.11 \pm 4.04$ & \\
\hline $\begin{array}{l}\text { ACR, mg per g } \\
\text { creatinine }\end{array}$ & $100.1 \pm 60.1$ & $94.57 \pm 56.65$ & $114.5 \pm 66.4$ & * \\
\hline $\begin{array}{l}\text { eGFR, } \mathrm{ml} \mathrm{min}^{-1} \\
\text { per } 1.73 \mathrm{~m}^{2}\end{array}$ & $70.8 \pm 20.5$ & $79.41 \pm 17.05$ & $48.79 \pm 8.66$ & $* * *$ \\
\hline $\mathrm{HbAlc}$ (NGSP), \% & $7.47 \pm 1.01$ & $7.55 \pm 1.03$ & $7.26 \pm 0.93$ & * \\
\hline $\mathrm{TG}, \mathrm{mmoll}^{-1}$ & $1.58 \pm 0.41$ & $1.62 \pm 1.15$ & $1.58 \pm 0.81$ & \\
\hline $\mathrm{HDL}, \mathrm{mmol}^{-1}$ & $1.45 \pm 0.41$ & $1.50 \pm 0.42$ & $1.32 \pm 0.34$ & ** \\
\hline LDL, mmoll-1 & $2.68 \pm 0.92$ & $2.63 \pm 0.98$ & $2.79 \pm 0.73$ & \\
\hline
\end{tabular}

Abbreviations: ACR, albumin-to-creatinine ratio; $\mathrm{BMI}$, body mass index; eGFR, estimated glomerular filtration rate; $\mathrm{HbAlc}$, hemoglobin $\mathrm{Alc}$; $\mathrm{HDL}$, high-density lipoprotein; $\mathrm{LDL}$, lowdensity lipoprotein; NGSP, National Glycohemoglobin Standardization Program; TG, triglyceride. Comparison between the preserved eGFR group and the low eGFR group.

${ }^{*} P<0.05,{ }^{* *} P<0.01$ and ${ }^{* * *} P<0.005$

Table 2 Baseline blood pressures of all patients, the preserved eGFR group and the low eGFR group

\begin{tabular}{lcccc}
\hline & \multicolumn{4}{c}{ Preserved } \\
& Total & eGFR & Low eGFR & P-value \\
\hline Proportion of patients & 94.0 & 92.8 & 97.3 & NS \\
with hypertension, \% & & & & \\
CSBP, mm Hg & $141.7 \pm 19.1$ & $142.1 \pm 18.3$ & $140.5 \pm 21.2$ & NS \\
CDBP, mm Hg & $76.7 \pm 11.3$ & $77.4 \pm 11.1$ & $74.9 \pm 11.7$ & NS \\
Morning HSBP, mm Hg & $137.7 \pm 16.4$ & $137.4 \pm 16.2$ & $138.3 \pm 17.0$ & NS \\
Morning HDBP, mm Hg & $75.4 \pm 10.1$ & $75.8 \pm 9.6$ & $74.4 \pm 11.4$ & NS \\
Evening HSBP, mm Hg & $131.6 \pm 14.3$ & $131.3 \pm 14.3$ & $132.2 \pm 14.4$ & NS \\
Evening HDBP, mm Hg & $70.7 \pm 9.6$ & $71.2 \pm 9.5$ & $69.3 \pm 9.9$ & NS \\
All HSBP, mm Hg & $134.6 \pm 14.5$ & $134.4 \pm 14.4$ & $135.2 \pm 14.7$ & NS \\
All HDBP, mm Hg & $73.0 \pm 9.4$ & $73.5 \pm 9.2$ & $71.9 \pm 10.1$ & NS \\
s.d. of HSBP, mm Hg & $10.3 \pm 4.3$ & $9.9 \pm 4.2$ & $11.2 \pm 4.61$ & $*$ \\
AHSBP, mm Hg & $35.2 \pm 15.4$ & $34.0 \pm 14.6$ & $38.2 \pm 17.1$ & $*$ \\
s.d. of HDBP, mm Hg & $6.4 \pm 2.7$ & $6.3 \pm 2.6$ & $6.7 \pm 3.0$ & NS \\
$\Delta$ HDBP, mm Hg & $21.7 \pm 9.5$ & $21.3 \pm 9.1$ & $22.7 \pm 10.6$ & NS \\
MEdif in HSBP, mm Hg & $6.1 \pm 10.7$ & $6.1 \pm 10.0$ & $6.1 \pm 12.4$ & NS \\
MEdif in HDBP, mm Hg & $4.7 \pm 5.9$ & $4.6 \pm 5.6$ & $5.1 \pm 6.6$ & NS \\
The number of antihyper- & $1.49 \pm 1.16$ & $1.30 \pm 1.06$ & $2.00 \pm 1.24$ & $* * * *$ \\
tensive drugs, drugs & & & & \\
The number of RAS & $0.72 \pm 0.54$ & $0.63 \pm 0.53$ & $0.93 \pm 0.50$ & $* * * *$ \\
blockade drugs, drugs & & & & \\
\hline
\end{tabular}

Abbreviations: CDBP, clinic diastolic blood pressure; CSBP, clinic systolic blood pressure; eGFR, estimated glomerular filtration rate; HDBP, home diastolic blood pressure; HSBP, home systolic blood pressure; Medif, morning-evening difference; NS, not significant; RAS, reninangiotensin system.

Comparison between the preserved eGFR group and the low eGFR group.

${ }^{*} P<0.05$ and ${ }^{* * * *} P<0.0001$

eGFR groups. However, the number of antihypertensive drugs and the number of renin-angiotensin system blockade drugs used in the low eGFR group was significantly higher than that for the patients in the preserved eGFR group $(P<0.0001)$. The variability in HBP was also compared between the two groups. The s.d. of the HSBP of the low eGFR group was significantly higher than that of the preserved eGFR
Table 3 Stepwise multiple linear regression analysis of the variability of HSBP with various variables

\begin{tabular}{lcccc}
\hline Variable & $\beta$ & s.e. & $t$ & P-value \\
\hline All HSBP & 0.292 & 0.018 & 4.903 & $<0.0001$ \\
eGFR (preserved or low) & 0.132 & 0.582 & 2.215 & 0.027 \\
Model $R^{2}=0.107, P<0.001$ & & & & \\
\hline
\end{tabular}

Abbreviations: eGFR, estimated glomerular filtration rate; HSBP, home systolic blood pressure. The s.d. of HSBP was included as independent variables.

The eGFR (preserved or low), all HSBP, age, gender, estimated duration of diabetes, body mass index, hemoglobin $\mathrm{A} 1 \mathrm{c}(\mathrm{HbAlc})$ and albumin-to-creatinine ratio (ACR) at baseline were originally included.

group $(P<0.05)$. The $\triangle$ HSBP was also significantly higher than that of the preserved eGFR group $(P<0.05)$. On the other hand, there was no significant difference in $\triangle \mathrm{HDBP}$ and the s.d. of the HDBP between the two groups. In addition, there were no significant differences in the MEdif of HSBP and HDBP between the two groups. A stepwise multiple linear regression analysis (probability of $\mathrm{P}$ in 0.05 , out 0.10 ) also revealed that the preserved and low eGFR groups were independently correlated with the s.d. of HSBP (Table 3).

Comparison of the clinical profiles of patients with and without a previous history of vascular complications

A total of 34 patients $(12.7 \%)$ had a previous history of $\mathrm{CHD}$ (Table 4). The patients with CHD were significantly older than those without CHD $(P<0.05)$. The estimated duration of diabetes was significantly longer in the patients with $\mathrm{CHD}(P<0.05)$. The prevalence of CHD was $22.7 \%$ in the low eGFR group and $8.8 \%$ in the preserved eGFR group $(P<0.005)$.

A total of 25 patients $(9.3 \%)$ had a previous history of stroke (Table 4). The clinical characteristics of the patients with and without stroke were similar. The prevalence of stroke was $14.7 \%$ in the low eGFR group and $7.3 \%$ in the preserved eGFR group.

The overall prevalence of advanced retinopathy in the patients was $27.0 \%$ (Table 4). Significant differences were observed in the estimated duration of diabetes $(P<0.005)$, CDBP $(P<0.05)$, morning HDBP $(P<0.005)$ and evening $\operatorname{HDBP}(P<0.05)$ between patients with and without advanced retinopathy. The prevalence of advanced retinopathy in the low eGFR group was $40.0 \%$, and was $21.9 \%$ in the preserved eGFR group $(P<0.005)$.

The results of a multiple logistic regression analysis with a previous history of CHD or advanced retinopathy as the dependent variables and the baseline variables listed in Table 4 as independent variables are shown in Table 5. A low eGFR was the only independent risk factor for CHD. The low eGFR group and the estimated duration of diabetes were independent risk factors for advanced retinopathy.

\section{DISCUSSION}

The proportion of patients in the low eGFR group was $28.0 \%$ in this study. This was higher than the proportion of low eGFR patients among the microalbuminuric diabetic patients reported by Yokoyama et al. ${ }^{13}$ The prevalence of hypertension in this study is $94.0 \%$. Hypertension was not included in the inclusion criteria for this study. However, the purpose of the present study is to establish the optimal HBP for the microalbuminuric diabetic patients. Therefore, hypertensive diabetic patients might have been preferably recruited for this study. A high prevalence of hypertension is one of the reasons for the high incidence of a low eGFR in the patients in this study.

The main finding of this study is that the variability of HSBP is significantly elevated in the low eGFR diabetic patients with 
Table 4 Comparison of the clinical profiles of patients with and without a previous history of vascular complications

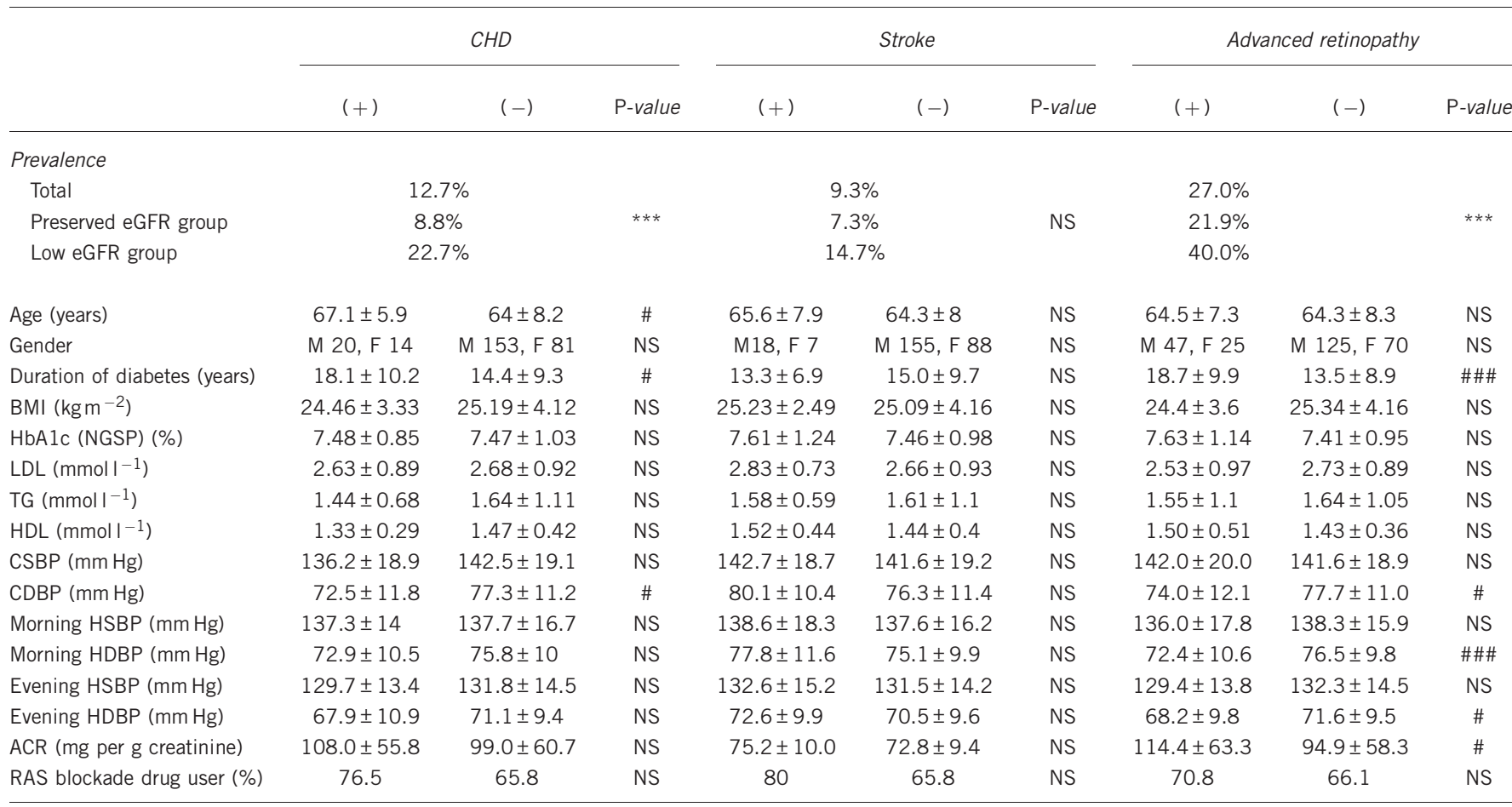

Abbreviations: ACR, albumin-to-creatinine ratio; BMI, body mass index; CDBP, clinic diastolic blood pressure; CHD, coronary heart disease; CSBP, clinic systolic blood pressure; eGFR, estimated glomerular filtration rate; F, female; HbAlc, hemoglobin Alc; HDBP, home diastolic blood pressure; HDL, high-density lipoprotein; HSBP, home systolic blood pressure; LDL, low-density lipoprotein; M, male; NGSP, National Glycohemoglobin Standardization Program; NS, not significant; RAS, renin-angiotensin system; TG, triglyceride.

Comparison between the preserved and the low eGFR groups, ${ }^{* * *} P<0.005$.

Comparison between patients with and without a previous history of vascular complications, ${ }^{\#} P<0.05$ and ${ }^{\# \#} P<0.005$.

Table 5 Risk factors for coronary heart disease and advanced retinopathy identified by a multiple logistic analysis

\begin{tabular}{lccc}
\hline & \multicolumn{3}{c}{ Coronary heart disease } \\
\cline { 2 - 4 } The dependent variable & OR & $(95 \% \mathrm{Cl})$ & $P$-value \\
\hline Low eGFR vs. preserved eGFR & 2.83 & $(1.32-6.05)$ & 0.007 \\
The dependent variable & \multicolumn{3}{c}{ Advanced retinopathy } \\
\cline { 2 - 4 } $\begin{array}{l}\text { Low eGFR vs. preserved eGFR } \\
\text { Duration of diabetes (years) }\end{array}$ & 2.16 & $(1.17-4.00)$ & 0.014 \\
\hline $\begin{array}{l}\text { Abbreviations: } \mathrm{Cl} \text {, confidence interval; eGFR, estimated glomerular filtration rate; OR, odds } \\
\text { ratio. } \\
\text { The model in which the baseline variables listed in Table 4 were originally included. }\end{array}$
\end{tabular}

microalbuminuria. Age, gender, blood pressure level and heart rate are significant determinants of elevated HBP variability. ${ }^{24,25}$ Macroalbuminuria is also determinant of elevated HBP variability in type 2 diabetic patients. ${ }^{26}$ However, no report has so far examined the relationship between GFR and the variability of blood pressure. We first demonstrated that the low eGFR was the explanatory variable for the variability of HBP independent of ACR, age, gender, duration of diabetes and HBP level. The MEdifs of HBP were similar in the low and preserved eGFR groups. Therefore, the elevated variability of HSBP might be derived from factors other than the MEdif of HSBP. Increased arterial stiffness and autonomic dysfunction might play a role in the elevated variability of HSBP observed in the low eGFR group. In this study, there were no significant differences in the variability of HDBP between the low and preserved eGFR groups.
However, the s.d. of the HDBP and the $\triangle \mathrm{HDBP}$ were slightly elevated in the low eGFR group. Evaluating more patients might be necessary to conclude whether the variability of HDBP is also elevated in the low eGFR group.

Second, the study compared the blood pressure and other clinical characteristics of the patients between the preserved eGFR group and low eGFR group. There were no significant differences in either the CBP or the HBP between the two groups. However, more antihypertensive drugs were used for the patients in the low eGFR group than for those in the preserved eGFR group. This means that the patients in the low eGRF group were more refractory to antihypertensive therapy. The HbAlc levels measured in the low eGFR group were significantly lower than those observed in the preserved eGFR group. This result is consistent with the findings in a report by Yokoyama et al..$^{13}$ and could be because of a reduced hemoglobin concentration caused by renal anemia, although our study did not collect data for hemoglobin concentrations.

Finally, the study examined whether a low eGFR was associated with vascular complications in type 2 diabetic patients with microalbuminuria. The results confirmed that a low eGFR was an independent risk factor for $\mathrm{CHD}$, as previously reported. ${ }^{16,17}$ Previous studies on the association between diabetic nephropathy and retinopathy have demonstrated that albuminuria is more closely related to advanced retinopathy than low eGFR without albuminuria. $^{27,28}$ However, there are no studies investigating the association between eGFR and retinopathy in microalbuminuric patients. We first demonstrated that a low eGFR is an independent risk factor for advanced retinopathy in microalbuminuric patients. Therefore, a low eGFR could be an indicator of microangiopathy as well as macroangiopathy. The GFR negatively correlates with the 
resistive index of the interlobular arteries. ${ }^{29}$ In addition, a reduced eGFR is associated with more advanced diabetic glomerular lesions in type 1 diabetic patients. ${ }^{30}$ Peritubular capillary loss leading to interstitial fibrosis is also reported to be correlated with impairment of the kidney function. ${ }^{31}$ Therefore, abnormalities in both small vessels and large vessels might affect the GFR. This could be one of the reasons why a low eGFR was an independent risk factor for both $\mathrm{CHD}$ and advanced retinopathy.

Most guidelines for treatment of hypertension including JHS 2009 recommend a CBP goal of $<130 / 80 \mathrm{mmHg}$ for patients with diabetes. ${ }^{9}$ However, there is not enough evidence that demonstrate the benefit of intensive BP control for the diabetic patients, especially for those with high risk of cardiovascular events. Intensive BP control increases the risk of adverse event. ${ }^{32,33}$ In addition, the incidence of stroke increases in patients with CKD stages 3 and 4, if the systolic blood pressure decreases to $<120 \mathrm{~mm} \mathrm{Hg}{ }^{34}$ The current study has demonstrated that microalbuminuric diabetic patients with low eGFR have a higher risk of getting vascular complications and higher variability of HBP than those with preserved eGFR. There could be more risk of lowering blood pressure too much in patients with high $\mathrm{BP}$ variability. Physicians should therefore exercise greater care when treating hypertensive patients with a low eGFR.

In conclusion, estimating the GFR of microalbuminuric patients is important to identify high-risk patients and those with more variation in day-by-day HBP. Therefore, measuring the HBP would be more helpful for the effective and safe treatment of hypertension for low eGFR patients than for the preserved eGFR patients. The results of this report are based on the baseline data of the HBP-DN study. Therefore, these conclusions should be confirmed in the future using the follow-up data from the HBP-DN study and in other cohorts of patients.

\section{CONFLICT OF INTEREST}

The authors declare no conflict of interest.

\section{ACKNOWLEDGEMENTS}

This work was executed as part of the National Hospital Organization MultiCenter Clinical Research for Evidence-Based Medicine and was supported by a National Hospital Organization collaborative clinical research grant. The following investigators are greatly thanked for participating in HBP-DN study: S Suzuki, K Yoshida, T Kohmura, N Ishida, I Yonezawa, S Taguchi, T Sugiyama, F Shimada, N Seki, M Ujihara, T Kimura, K Maruyama, M Takeuchi, Y Andou, K Kouyama, H Taki, K Kawada, M Saitou, N Nagase, $\mathrm{H}$ Hashida, T Toyonaga and N Koriyama.

1 Adler AI, Stevens RJ, Manley SE, Bilous RW, Cull CA, Holman RRUKPDS GROUP. Development and progression of nephropathy in type 2 diabetes: the United Kingdom Prospective Diabetes Study (UKPDS 64). Kidney Int 2003; 63: 225-232.

2 Perkins BA, Ficociello LH, Silva KH, Finkelstein DM, Warram JH, Krolewski AS Regression of microalbuminuria in type 1 diabetes. N Engl J Med 2003; 348: 2285-2293.

3 Araki S, Haneda M, Sugimoto T, Isono M, Isshiki K, Kashiwagi A, Koya D. Factors associated with frequent remission of microalbuminuria in patients with type 2 diabetes. Diabetes 2005; 54: 2983-2987.

4 Cappuccio FP, Kerry SM, Forbes L, Donald A. Blood pressure control by home monitoring: meta-analysis of randomised trials. BMJ 2004; 329: 145

5 Ohkubo T, Imai Y, Tsuji I, Nagai K, Kato J, Kikuchi N, Nishiyama A, Aihara A, Sekino M, Kikuya M, Ito S, Satoh H, Hisamichi S. Home blood pressure measurement has a stronger predictive power for mortality than does screening blood pressure measurement: a population-based observation in Ohasama, Japan. J Hypertens 1998; 16: 971-975.

6 Bobrie G, Chatellier G, Genes N, Clerson P, Vaur L, Vaisse B, Menard J, Mallion JM Cardiovascular prognosis of "masked hypertension" detected by blood pressure selfmeasurement in elderly treated hypertensive patients. JAMA 2004; 291: 1342-1349.
7 Agarwal R, Andersen MJ. Prognostic importance of clinic and home blood pressure recordings in patients with chronic kidney disease. Kidney Int 2006; 69: 406-411.

8 Nishimura M, Kato M, Shimada F, Kato Y, Todo R, Ando Y, Hida K, Iseda I, Tone A, Nagase N, Yoshizumi H, Higashi K, Hoshiyama Y. Prognostic importance of home blood pressure measurement in patients with diabetic nephropathy. Diabetol Int 2011; 2: 10-18.

9 Ogihara T, Kikuchi K, Matsuoka H, Fujita T, Higaki J, Horiuchi M, Imai Y, Imaizumi T, Ito S, Iwao H, Kario K, Kawano Y, Kim-Mitsuyama S, Kimura G, Matsubara H, Matsuura H, Naruse M, Saito I, Shimada K, Shimamoto K, Suzuki H, Takishita S, Tanahashi N, Tsuchihashi T, Uchiyama M, Ueda S, Ueshima H, Umemura S, Ishimitsu T, Rakugi HJapanese Society of Hypertension Committee. The Japanese Society of Hypertension Guidelines for the Management of Hypertension (JSH 2009). Hypertens Res 2009; 32: 3-107.

10 Imai Y, Kario K, Shimada K, Kawano Y, Hasebe N, Matsuura H, Tsuchihashi T, Ohkubo T, Kuwajima I, Miyakawa MJapanese Society of Hypertension Committee for Guidelines for Self-monitoring of Blood Pressure at Home. The Japanease Society of Hypertension Guidelines for Self-Monitoring of Blood Pressure at Home (Second Edition). Hypertens Res 2012; 35: 777-795.

11 Kramer HJ, Nguyen QD, Curhan G, Hsu CY. Renal insufficiency in the absence of albuminuria and retinopathy among adults with type 2 diabetes mellitus. JAMA 2003; 289: 3273-3277.

12 Kramer CK, Leitão CB, Pinto LC, Silveiro SP, Gross JL, Canani LH. Clinical and laboratory profile of patients with type 2 diabetes with low glomerular filtration rate and normoalbuminuria.. Diabetes Care 2007; 30: 1998-2000.

13 Yokoyama H, Sone H, Oishi M, Kawai K, Fukumoto Y, Kobayashi M. Japan Diabetes Clinical Data Management Study GroupPrevalence of albuminuria and renal insufficiency and associated clinical factors in type 2 diabetes: the Japan Diabetes Clinical Data Management study (JDDM15). Nephrol Dial Transplant 2009; 24: 1212-1219.

14 Retnakaran R, Cull CA, Thorne KI, Adler AI, Holman RRUKPDS Study Group. Risk factors for renal dysfunction in type 2 diabetes: U.K. Prospective Diabetes Study 74. Diabetes 2006; 55: 1832-1839.

15 American Diabetes Association. Standards of Medical Care in Diabetes -2011. Diabetes Care 2011; 34: S11-S61.

16 Ninomiya T, Perkovic V, de Galan BE, Zoungas S, Pillai A, Jardine M, Patel A, Cass A, Neal B, Poulter N, Mogensen CE, Cooper M, Marre M, Williams B, Hamet P, Mancia G, Woodward M, Macmahon S, Chalmers JADVANCE Collaborative Group. Albuminuria and kidney function independently predict cardiovascular and renal outcomes in diabetes. J Am Soc Nephrol 2009; 20: 1813-1821.

17 Chronic Kidney Disease Prognosis ConsortiumMatsushita K, van der Velde M, Astor BC, Woodward M, Levey AS, de Jong PE, Coresh J, Gansevoort RT. Association of estimated glomerular filtration rate and albuminuria with all-cause and cardiovascular mortality in general population cohorts: a collaborative meta-analysis. Lancet 2010; 375: 2073-2081.

18 Rothwell PM, Howard SC, Dolan E, O'Brien E, Dobson JE, Dahlöf B, Sever PS, Poulter NR. Prognostic significance of visit-to-visit variability, maximum systolic blood pressure, and episodic hypertension. Lancet 2010; 375: 895-905.

19 Kikuya M, Ohkubo T, Metoki H, Asayama K, Hara A, Obara T, Inoue R, Hoshi H, Hashimoto J, Totsune K, Satoh H, Imai Y. Day-by-day variability of blood pressure and heart rate at home as a novel predictor of prognosis: the Ohasama study. Hypertension 2008; 52: 1045-1050.

20 Matsui Y, Eguchi K, Shibasaki S, Shimizu M, Ishikawa J, Shimada K, Kario K. Association between the morning-evening difference in home blood pressure and cardiac damage in untreated hypertensive patients. J Hypertens 2009; 27: 712-720.

21 Matsui Y, Ishikawa J, Eguchi K, Shibasaki S, Shimada K, Kario K. Maximum value of home blood pressure: a novel indicator of target organ damage in hypertension. Hypertension 2011; 57: 1087-1093.

22 Imai E, Horio M, Nitta K, Yamagata K, Iseki K, Tsukamoto Y, Ito S, Makino H, Hishida A, Matsuo S. Modification of the Modification of Diet in Renal Disease (MDRD) Study equation for Japan. Am J Kidney Dis 2007; 50: 927-937.

23 National Kidney Foundation. K/DOQI clinical practice guidelines for chronic kidney disease: evaluation, classification, and stratification. Am J Kidney Dis 2002; 39 (Suppl 1), S1-S266.

24 Johansson JK, Niiranen TJ, Puukka PJ, Jula AM. Factors affecting the variability of home-measured blood pressure and heart rate: the Finn-home study. J Hypertens 2010; 28: 1836-1845.

25 Kato T, Kikuya M, Ohkubo T, Satoh M, Hara A, Obara T, Metoki H, Asayama K, Hirose T, Inoue R, Kanno A, Totsune K, Hoshi H, Satoh H, Imai Y. Factors associated with day-by-day variability of self-measured blood pressure at home: the Ohasama study. Am J Hypertens 2010; 23: 980-986.

26 Ushigome E, Fukui M, Hamaguchi M, Senmaru T, Sakabe K, Tanaka M, Yamazaki M, Hasegawa G, Nakamura N. The coefficient variation of home blood pressure is a novel factor associated with macroalbuminuria in type 2 diabetes mellitus. Hypertens Res 2011; 34: 1271-1275.

27 Chen YH, Chen HS, Tarng DC. More impact of microalbuminuria on retinopathy than moderately reduced GFR among type 2 diabetic patients. Diabetes Care 2012; 35: 803-808.

28 Penno G, Solini A, Zoppini G, Orsi E, Zerbini G, Trevisan R, Gruden G, Cavalot F, Laviola L, Morano S, Nicolucci A, Pugliese Gfor the Renal Insufficiency And Cardiovascular Events (RIACE) Study Group.. Rate and determinants of association between advanced retinopathy and chronic kidney disease in patients with type 2 
diabetes: the Renal Insufficiency And Cardiovascular Events (RIACE) Italian multicenter study. Diabetes Care35: 2317-2323 2012.

29 Maclsaac RJ, Panagiotopoulos S, McNeil KJ, Smith TJ, Tsalamandris C, Hao H Matthews PG, Thomas MC, Power DA, Jerums G. Is nonalbuminuric renal insufficiency in type 2 diabetes related to an increase in intrarenal vascular disease? Diabetes Care 2006; 29: 1560-1566.

30 Caramori ML, Fioretto P, Mauer M. Low glomerular filtration rate in normoalbuminuric type 1 diabetic patients: an indicator of more advanced glomerular lesions. Diabetes 2003; 52: 1036-1040.

31 Metcalfe W. How does early chronic kidney disease progress? A background paper prepared for the UK Consensus Conference on early chronic kidney disease.. Nephro Dial Transplant 2007; 22 (Suppl 9), ix26-ix30.
32 ACCORD Study Group, Cushman WC, Evans GW, Byington RP, Goff DC Jr, Grimm RH Jr, Cutler JA, Simons-Morton DG, Basile JN, Corson MA, Probstfield JL, Katz L, Peterson KA, Friedewald WT, Buse JB, Bigger JT, Gerstein HC, Ismail-Beigi F. Effects of intensive blood-pressure control in type 2 diabetes mellitus. N Engl J Med 2010; 362: 1575-1585.

33 Bangalore S, Kumar S, Lobach I, Messerli FH. Blood pressure targets in subjects with type 2 diabetes mellitus/impaired fasting glucose: observations from traditional and bayesian random-effects meta-analyses of randomized trials. Circulation 2011; 123 2799-2810.

34 Weiner DE, Tighiouart H, Levey AS, Elsayed E, Griffith JL, Salem DN, Sarnak MJ. Lowest systolic blood pressure is associated with stroke in stages 3 to 4 chronic kidney disease. J Am Soc Nephrol 2007; 18: 960-966. 